\title{
Adherence to disease-modifying treatments in patients with multiple sclerosis in Spain
}

This article was published in the following Dove Medical Press journal:

Patient Preference and Adherence

\author{
Ramón Morillo Verdugo' \\ Esther Ramírez Herráiz ${ }^{2}$ \\ Raquel Fernández-Del \\ $\mathrm{Olmo}^{3}$ \\ Montserrat Roig Bonet ${ }^{4}$ \\ María Valdivia García ${ }^{5}$ \\ 'Valme University Hospital, Seville, \\ Spain; ${ }^{2}$ La Princesa University \\ Hospital, Madrid, Spain; ${ }^{3}$ Market \\ Access Department, Roche Farma, \\ S.A., Madrid, Spain; ${ }^{4}$ Project \\ Department, Technical Advisory of \\ Projects and Innovation "Esclerosis \\ Múltiple España”, Madrid, Spain; \\ ${ }^{5}$ Fundación de Esclerosis Múltiple \\ Madrid, Madrid, Spain
}

\begin{abstract}
Purpose: Adherence to disease-modifying treatments is essential in order to maximize the beneficial effects of treatment for multiple sclerosis (MS). There are numerous treatments that have been approved. Treatment selection is essential in patient adherence. In addition, patient preference plays an increasingly significant role in treatment decision-making. This study aims to evaluate the degree of adherence, along with other variables that may influence this adherence, in Spain.

Methods: A cross-sectional study was conducted with 157 MS patients with disease-modifying treatments. Adherence was assessed using the Morisky Green scale, and other related factors were measured using a questionnaire that addressed demographics, disease characteristics, global perception of pathology, impact of medication on patient's life, and treatment decision-making. Results: The adherence rate was $71 \%$ and was associated with the following variables: older age, more treatments received, time to diagnosis 5-10 years, absence of exacerbations, better cognitive status, being married/in a union, clear information about the disease, and higher treatment satisfaction. The main cause for non-compliance was forgetfulness (27\%).

Conclusion: The adherence rate is acceptable. It is widely known that treatment satisfaction is related to adherence. In our study, patients' level of satisfaction was higher with oral treatments. However, oral administration showed a greater lack of adherence. The main cause of lack of adherence was forgetfulness. In relation to other variables, cognitive status and family support showed a correlation with treatment adherence.
\end{abstract}

Keywords: treatment adherence, oral administration, injectable administration, treatment satisfaction

\section{Introduction}

Multiple sclerosis (MS) is a chronic, unpredictable, degenerative autoimmune inflammatory disease that affects the central nervous system. In general, it begins with an acute inflammatory demyelinating incident followed by new clinical episodes, leading to a diagnosis of relapsing-remitting MS (RRMS). Two-thirds of these patients develop secondary progressive MS (SPMS). In Europe, between 7\% (Spain) and 27\% (the Netherlands) of cases involve the primary progressive MS (PPMS) form. ${ }^{2}$

MS causes demyelination and axonal damage in the brain and spinal cord,,$^{3,4}$ which implies a high probability of increasing neurological disability. This is the most common neurological disorder leading to disability in young adulthood, ${ }^{5}$ affecting 2.3 million people worldwide. ${ }^{6}$ The most common symptoms of MS exacerbations include paresthesia; motor symptoms; muscle cramping or spasticity; spinal cord symptoms; bladder, bowel, or sexual dysfunction; and fatigue. ${ }^{7}$

To date, MS is still an incurable disease. Treatments are designed to modify the natural evolution of the illness (reducing relapse and disability progression rates)
Correspondence: Ramón Morillo Verdugo

Valme University Hospital, Carretera de Cádiz s/n., Seville 41014 , Spain

$\mathrm{Tel}+3495015467$

Fax +3495 0l 546 I

Email ralejandro.morillo.sspa@ juntadeandalucia.es
Patient Preference and Adherence 2019:13 261-272

261

Dovepress f $y$ in $\mathbf{0}$

http:

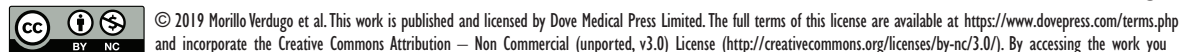
$\mathrm{BY}$
he for commercial use of this work, please see paragraphs 4.2 and 5 of our Terms (https://www.dovepress.com/terms.php). 
with disease-modifying therapies (DMTs) or to alleviate symptoms (reducing inflammation) to improve the patient's quality of life. . $^{7,8}$

MS treatment involves a high consumption of health care resources, resulting in significant costs with a high impact on health facilities. In Europe, the annual cost of MS management ranged from $€ 22,800$ in mild cases to $€ 57,500$ in severe cases. ${ }^{2}$ In Spain, this cost was $€ 23,157$ and $€ 29,242$ in mild and severe cases, respectively, demonstrating elevated costs for the Spanish National Health System. Costs are significantly correlated with disease progression. ${ }^{9}$

Adherence to therapy, especially in chronic cases, is crucial in order for patients to obtain a clinical benefit, although adherence data for other chronic diseases were scarce. ${ }^{10}$ Lack of adherence is associated with increased morbidity, mortality, and health care costs. ${ }^{11}$ In MS, therapy adherence varies widely (60\%-90\% with DMTs),${ }^{8}$ and non-adherence has been associated with increased MS-related hospitalizations and relapse rates. ${ }^{12}$

Several factors have been associated with therapy adherence, including age, sex, socioeconomic status, comorbidity, perceived lack of efficacy, MS type, patient attitude, adverse drug effects, forgetfulness, depression, anxiety, and cognitive difficulties. ${ }^{13,14}$ Therefore, a better understanding of these factors would increase understanding of MS-treatment adherence, providing useful information for treatment choice. The aim of this study is to evaluate the degree of adherence in MS patients in Spain, and the influence of several variables on this adherence. Secondary aims are to examine patients' satisfaction with their treatment and reasons for changing treatment.

\section{Materials and methods Study design and population}

This is a cross-sectional study using a questionnaire to assess adherence to MS treatments. The study was carried out in Spain between June 2017 and September 2017. Data were collected by phone interviews lasting 15-20 minutes.

The study's population consisted of MS patients (with diagnoses of RRMS, SPMS, and PPMS) aged $\geq 18$ years, who had been receiving pharmacologic treatment for at least 1 year. Considering there are 47,000 MS patients in Spain (based on data from the Spanish Society of Neurology), the calculated sample size was 157 , with a sampling error of $\pm 7.8 \%$ at a $95.5 \%$ confidence level. Patients were recruited at hospitals and patients associations by health care professionals (physicians and nurses) and patients association staff, who contacted patients and explained the study. This is a market research that is exempt from approval by a research ethics committee according to Spanish legislation and was conducted in accordance with the EphMRA (European Pharmaceutical Market Research Association) guidelines. Written informed consent was obtained from all patients.

Several variables were controlled for in order to ensure that the sample was representative and to avoid bias. The approximate quotas were set as the following: percentage of MS type according to the known data, current number of treatments, and type of treatment received (ABCR drugs, oral, high-efficacy). In addition, $<50 \%$ of the sample belonged to patients associations.

\section{Variables and measurements}

The main variable of the study was self-reported adherence to current MS treatments in the previous 6 months, according to the Morisky Green (MG) test. ${ }^{15}$ The MG test, validated in the Spanish language, ${ }^{16}$ was selected because of its reliability $(61 \%) .{ }^{15}$ The degree of treatment adherence was determined by calculating the sum of all correct answers to question P7. The patient was considered as compliant if the answers to the four questions of P7were: NO/YES/NO/NO (Table 1).

The variables assessed in the study were compiled in a questionnaire, elaborated on and validated by an MS expert committee made up of hospital pharmacists, a neurologist, and professionals, including a nurse from FEMM (Fundación Esclerosis Múltiple Madrid) and a clinical psychologist from EME (Esclerosis Múltiple España). The questionnaire had 57 items structured in seven areas: 1) Sociodemographic and pathology data (12 items); 2) MS information (four items); 3) Current MS treatment (adherence to current treatment) (13 items); 4) Interruptions of current MS treatment (six items); 5) Adherence to previous treatment (eight items); 6) Profile of patient's attitude (one item); and 7) Patient and pathology characteristics (13 items). The items were graded through metrics, scales (1-10), multiple responses, and categories (Table 1).

\section{Statistical analysis}

Descriptive statistics were used to present both quantitative and qualitative variables. Data were expressed as absolute values and percentages (qualitative variables), and summarized using descriptive statistics, such as the mean and $\mathrm{SD}$ (quantitative variables). With regard to missing values: once the interview was carried out, if a participant did not answer a specific question, it was considered as not known/ not available in the analysis. 
Table I Questionnaire: evaluated variables

\begin{tabular}{|c|c|}
\hline I. Sociodemographic and pathology data & Response \\
\hline FI. Spanish province & \\
\hline F2. Birth year & \\
\hline F3. Gender & \\
\hline F4. MS type & \\
\hline F5. How long have you been receiving medication to treat your MS? & \\
\hline F5b. In what year did you start taking medication to treat MS? & \\
\hline F6. How many treatments have you received since you started taking medication for MS? & \\
\hline F7. What is the medication you are currently receiving for MS? & \\
\hline F8. If $\mathrm{F} 6$ response $\geq \mathrm{I}$. What was the medication you received for MS? & \\
\hline F9. If F6 response $>2$. Before this, do you remember what was the medication you received for MS? & \\
\hline FIO. Do you belong to any patients association? & \\
\hline FIOb. Which? & \\
\hline 2. MS information & Response (scale I-I0) \\
\hline $\begin{array}{l}\text { PI. To what extent do you consider medication for MS important? Rate with a grade from I to I0, where I is } \\
\text { "Not at all important" and I0 "Very important" }\end{array}$ & \\
\hline $\begin{array}{l}\text { P2. To what extent do you consider it important to correctly follow the indications about taking your } \\
\text { medication for MS? Rate with a grade from I to I0, where I is "Not at all important" and I0 "Very } \\
\text { important" }\end{array}$ & \\
\hline $\begin{array}{l}\text { P3. To what extent do you think that the INFORMATION that you have received from health professionals } \\
\text { about the treatment of MS has been sufficiently CLEAR enough? Rate with a grade from I to I0, where I is } \\
\text { "Not at all clear" and I0 "Very clear" }\end{array}$ & \\
\hline $\begin{array}{l}\text { P4. Rate with a grade from I to I0, where I is "I do not care about anything" and I0 "I'm very worried" } \\
\text { To what extent do you worry about the following aspects of your medication for MS? } \\
\text { - Possible mild side effects } \\
\text { - Possible serious side effects } \\
\text { - (If }>45 \text {, do not ask) the possible interference with pregnancy } \\
\text { - The way to take/administer the medication } \\
\text { - The slowness in its effect/benefit } \\
\text { - The impact of medication on your daily life }\end{array}$ & \\
\hline 3. Current MS treatment (adherence to current treatment) & Response \\
\hline P5. What is the name of the medication you are currently receiving for MS? & \\
\hline P6. How long have you been taking your current medication? & \\
\hline $\begin{array}{l}\text { P7. (Morisky-Green test) Next, focus on the last } 6 \text { months and on the medication you are currently receiving } \\
\text { for MS. } \\
\text { - I= Do you ever forget to take medications to treat your illness? } \\
\text { - } 2 \text { = Do you take the medications at the indicated times? } \\
\text { - } 3 \text { = When you are well, do you stop taking the medication? } \\
\text { - } 4=\text { If you ever feel bad, do you stop taking it? }\end{array}$ & \\
\hline P7b. If response P7_2=2. Why? & \\
\hline P8. If response P7_I=I. Have you forgotten any dose in the last 30 days? & \\
\hline $\begin{array}{l}\text { P9. If response P7_I=I. What do you do when you forget a shot of your current medication? } \\
\text { - I=I do not take it and wait until the next shot } \\
\text { - } 2=\text { I take it the moment I remember } \\
\text { - } 3=\text { In the next shot, I take two (double the dose) } \\
\text { - Other (specify) }\end{array}$ & \\
\hline $\begin{array}{l}\text { PI0. If response P7_I or P7_3 or P7_4=I. If you forget or stop taking any dose, do you communicate it to } \\
\text { your ...? } \\
\text { - Doctor } \\
\text { - Nurse } \\
\text { - Hospital pharmacist } \\
\text { - Other (specify) }\end{array}$ & \\
\hline
\end{tabular}


Table I (Continued)

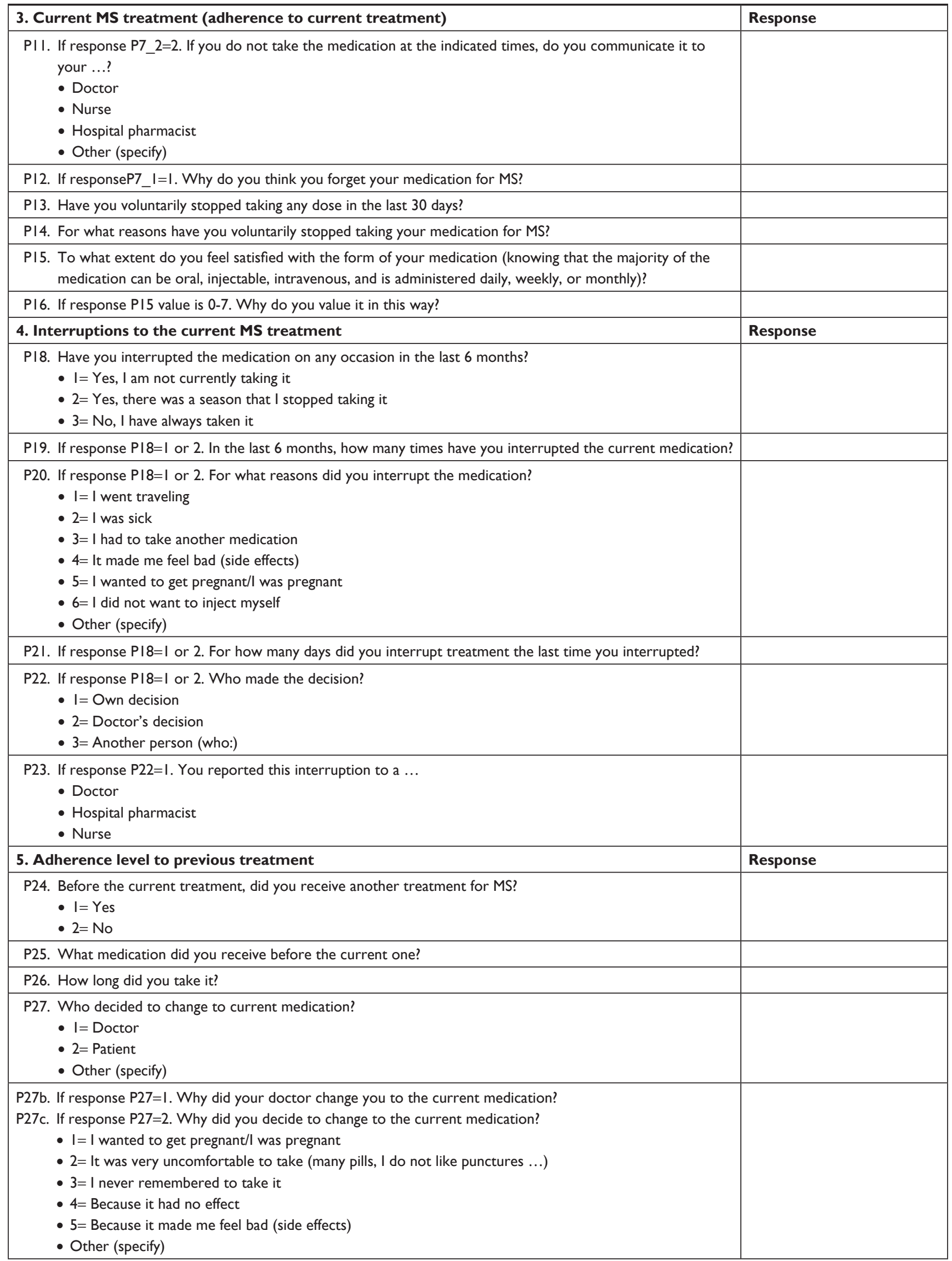


Table I (Continued)

\begin{tabular}{|c|}
\hline 5. Adherence level to previous treatment \\
\hline $\begin{array}{l}\text { P28. With what do you think you are more adherent? } \\
\text { - } I=\text { Current } \\
\text { - } 2=\text { Previous }\end{array}$ \\
\hline $\begin{array}{l}\text { P29. Why? } \\
\text { - I= Administration frequency } \\
\text { - } 2=\text { Administration route } \\
\text { - Other (specify) }\end{array}$ \\
\hline 6. Patient attitudinal profile \\
\hline $\begin{array}{l}\text { P30. There are } 3 \text { patient profiles. You may identify with some aspects of the } \\
\text { with which of the three do you feel more identified with today in relatio } \\
\text { If you had to choose only one? } \\
\text { - I= I feel that I can continue living the life that I want and although som } \\
\text { situation, I can find a way to do it since I am a practical person. My att } \\
\text { is proactive, realistic, and open to new options } \\
\text { - } 2=\text { Sometimes I feel that neither the doctors nor my family understan } \\
\text { my illness is concerned, I feel alone and not very optimistic in the evol } \\
\text { that the treatments can provide me } \\
\text { - } 3=\text { I have learned to live day by day since nobody knows what can hap } \\
\text { pragmatism are my main values. "Carpe diem" is a philosophy of life. I } \\
\text { and the treatment by showing an open attitude, without worrying too } \\
\text { they come }\end{array}$ \\
\hline 7. Patient and pathology characteristics \\
\hline P3I. In what year were you diagnosed with MS? \\
\hline $\begin{array}{l}\text { P32. Have you suffered any exacerbation in the last year? } \\
\begin{array}{l}-1=\text { Yes } \\
-2=\text { No }\end{array}\end{array}$ \\
\hline P33. If response $\mathrm{P} 32=\mathrm{I}$. How many exacerbations have you had in the last yea \\
\hline P34. How many months have passed since you had the last exacerbation? \\
\hline P35. How many months have passed between the last exacerbation and the $P$ \\
\hline P36. In the last year, how many hospital admissions do you remember were $c$ \\
\hline $\begin{array}{l}\text { P37. Do you have any impairment/disability caused by MS? } \\
-1=\text { Yes } \rightarrow \text { What? } \\
\text { - } 2=\text { No }\end{array}$ \\
\hline $\begin{array}{l}\text { P38. Would you mind telling me what your marital status is? } \\
\text { - I= Single } \\
\text { - } 2=\text { Married } \\
\text { - } 3=\text { Divorced } \\
\text { - Widow(er) }\end{array}$ \\
\hline $\begin{array}{l}\text { P39. Do you need your family's help or outside help for your day-to-day life? } \\
\text { - I= Yes } \rightarrow \text { What? } \\
\text { - } 2=\text { No }\end{array}$ \\
\hline $\begin{array}{l}\text { P40. What other health problems do you have besides MS? } \\
\text { - I= Hypertension } \\
\text { - } 2=\text { High cholesterol } \\
\text { - } 3=\text { Diabetes mellitus } \\
\text { - } 4=\text { Renal problems (acute/chronic renal failure, lithiasis ...) } \\
\text { - } 5=\text { Cardiac problems (acute myocardial infarction, heart failure ...) } \\
\text { - } 6=\text { Respiratory problems (asthma, chronic bronchitis, lung edema ...) } \\
\text { - } 7=\text { Urologic problems } \\
\text { - Other (specify) } \\
\text { - No more }\end{array}$ \\
\hline $\begin{array}{l}\text { P4I. Should you take other medications to control these problems? } \\
\text { - I= Hypertension } \\
\text { - } 2 \text { = High cholesterol }\end{array}$ \\
\hline
\end{tabular}


Table I (Continued)

\begin{tabular}{|l|l|}
\hline 7. Patient and pathology characteristics & Response \\
\hline - $3=$ Diabetes mellitus & \\
- $4=$ Renal problems & \\
- $5=$ Cardiac problems & \\
- $6=$ Respiratory problems & \\
- Other & \\
\hline P42. From a scale of I to 10, to what extent do you comply with what is indicated by the doctor when taking & \\
these other medications? & \\
\hline P43. What is your employment status? & \\
- I= Employed & \\
- $2=$ Unemployed & \\
\hline
\end{tabular}

Abbreviation: MS, multiple sclerosis.

The minimum level of significance was set at $P<0.05$. BarbWin version 7 (Tesi S.L., Spain) was used for obtaining the distributions (in absolutes and percentages) and the different statistics (mean and SD). IBM SPSS Statistics version 23 (SPSS Inc., Chicago, IL, USA) was used to conduct the significant tests: Student's $t$-distribution (mean) and chi-square (percentages).

\section{Results}

There were 163 patients who agreed to participate in the investigation. Of these, 157 adult MS patients who had been treated for $\geq 1$ year and were evenly distributed throughout all regions in Spain, met all the criteria to complete the survey and were included in the study (Table 2).

\section{Sociodemographic characteristics}

The mean age of patients included in the study was 43.9 years (SD \pm 10.9 ), and $72 \%$ were women. The study population quotas were the following: MS type (RRMS, 75\%; SPMS, 18\%; and PPMS, 7\%), line of treatment (first-line, 58\%; second-line, 29\%; and third-line, 14\%), treatment type (ABCR, 47\%; oral, 38\%; and high-efficacy, 15\%), and membership in patients associations (yes, 47\% and no, $53 \%$ ). The patients' sociodemographic characteristics are summarized in Table 2.

\section{Disease characteristics}

The most common MS type was RRMS, followed by SPMS and PPMS. The mean time to diagnosis was 10.1 years, and $45 \%$ of patients had a diagnosis in $>10$ years. The mean treatment duration was 8.8 years. Forty-eight percent of patients remained in their first treatment, 31\% in their second, and $21 \%$ in their third or later treatment. During the last year, only $11 \%$ of patients were hospitalized due to MS.
The mean duration of a period free of exacerbations was 31 months. In the last year, $31 \%$ of patients had exacerbations: $1(70 \%), 2(22 \%)$, and $\geq 3(8 \%)$, with a mean time of 18 months since the previous exacerbation.

MS-related symptoms/impairments were reported by $72 \%$ of patients; $71 \%$ of them with mobility impairment. Other symptoms included: fatigue or loss of strength (29\%);

Table 2 Sociodemographic characteristics of MS patients

\begin{tabular}{|l|l|l|}
\hline Variables (n=157) & $\mathbf{n}$ & $\%$ \\
\hline Localization in Spain & & \\
North & 28 & 18 \\
North East & 34 & 22 \\
Center & 35 & 22 \\
East & 28 & 18 \\
South & 32 & 20 \\
Age (years) & & \\
$<40$ & 60 & 38 \\
$40-49$ & 52 & 33 \\
$>50$ & 45 & 29 \\
Gender & & \\
Male & 44 & 28 \\
Female & 113 & 72 \\
Marital status & & \\
Married & 90 & 57 \\
Single & 52 & 33 \\
Divorced & 10 & 6 \\
Widow(er) & 4 & 3 \\
Nk/Na & 1 & 1 \\
Employment status & & \\
Employed & 56 & 37 \\
Unemployed & 101 & 63 \\
Localization & 99 & \\
Urban area & 58 & \\
Rural area & 74 & \\
Patients associations & & \\
Yes & 83 & \\
No & & \\
\hline Abbriations MS, ma & \\
\hline
\end{tabular}

Abbreviations: $\mathrm{MS}$, multiple sclerosis; $\mathrm{Nk} / \mathrm{Na}$, not known/not available. 
visual, hearing, or vocal impairments (20\%); lack of sensibility or cramps (20\%); genitourinary impairments $(7 \%)$; and cognitive impairments (7\%). Help from third parties was required by $42 \%$ of patients, mainly for household chores (41\%) and assistance in moving (29\%).

Fifty-four percent of patients reported no comorbidities. Among the remaining patients who mentioned other health problems, $11 \%$ reported hypercholesterolemia, $10 \%$ urologic disorders, and $8 \%$ hypertension. Compliance with comorbidities treatment as reported by patients was high (mean: 8.9/10).

\section{Current MS treatment and its impact}

Current MS treatment in most patients was by injections (62\%: 26\% intravenous [IV] and 74\% subcutaneous [SC], vs oral treatment [38\%]). The current mean duration of treatment ranged between 14.2 and 96.7 months: oral (21.6-44.0 months, with less time in use) and injectable (14.2-96.7 months). Patient satisfaction for the type of administration was higher with oral route (mean: 8.6/10) than with injectable treatment (mean: 7.6/10) $(P<0.05)$.

Patients' scores (on a scale of $1-10$, where $1=$ not important and $10=$ very important) for the following aspects of their disease were high: A) medication importance: 9.1 ; B) importance of following the indications: 9.5 ; and $\mathrm{C}$ ) clarity of the information received: 8.8 (where $1=$ not clear and $10=$ very clear).

Patients' concerns regarding MS medication were evaluated. Patients considered the possible serious side effects (75\%) of medication to be of most concern (scores: 8-10/10). Additional concerns that were not as worrying included; slowness of effect/benefit (59\%); the medication's impact on daily life (55\%); the form of drug administration (55\%); potential interference with pregnancy $(51 \%)$; and possible mild side effects $(47 \%)$. With regard to possible mild side effects, patients with IV administration showed a statistically greater concern $(72 \%, P<0.05)$ in comparison with $\mathrm{SC}(43 \%)$ and oral (42\%) administration.

\section{Adherence analysis of current treatment}

Adherence was $71 \%$. There were no differences based on the administration route (oral [63\%] vs injectable [77\%], $P=0.064)$. However, in injectable administration, there was greater adherence in patients with IV $(100 \%)$ than those with SC $(68 \%)(P=0.003)$; Table 3 . There was also a significantly greater difference between adherence to IV (100\%) and oral (63\%) treatment $(P=0.001)$.

Among oral treatments, the highest non-compliance rate appeared in patients receiving dimethyl fumarate $(65 \%)$,
Table 3 Adherence according to administration route

\begin{tabular}{|c|c|c|c|c|}
\hline & \multirow[t]{2}{*}{$\begin{array}{l}\text { Oral (\%) } \\
(n=59)\end{array}$} & \multicolumn{2}{|c|}{$\begin{array}{l}\text { Injectable (\%) } \\
(\mathrm{n}=98)\end{array}$} & \multirow[t]{2}{*}{$P$-value } \\
\hline & & $\begin{array}{l}\text { IV (\%) } \\
(n=25)\end{array}$ & $\begin{array}{l}\text { SC (\%) } \\
(n=73)\end{array}$ & \\
\hline Compliance & 63 & $\begin{array}{l}77 \\
100\end{array}$ & 68 & $\begin{array}{l}0.064 \\
\mathbf{0 . 0 0 3}\end{array}$ \\
\hline Forgetfulness & 36 & $\begin{array}{l}22 \\
0\end{array}$ & 30 & $\begin{array}{l}0.109 \\
0.005\end{array}$ \\
\hline $\begin{array}{l}\text { Patient takes the } \\
\text { medication at indicated } \\
\text { hours }\end{array}$ & 95 & $\begin{array}{l}96 \\
100\end{array}$ & 94 & $\begin{array}{l}1.000 \\
0.542\end{array}$ \\
\hline $\begin{array}{l}\text { Patient does not take the } \\
\text { medication if feeling well } \\
\text { Patient does not take the } \\
\text { medication if feeling bad }\end{array}$ & 0 & $\begin{array}{l}1 \\
0 \\
1 \\
0\end{array}$ & $\begin{array}{l}1 \\
1\end{array}$ & $\begin{array}{l}1.000 \\
1.000 \\
0.654 \\
1.000\end{array}$ \\
\hline
\end{tabular}

Notes: Bold values indicate statistical significance.

Abbreviations: IV, intravenous; SC, subcutaneous.

followed by fingolimod (29\%) and teriflunomide (7\%). With regard to injectable drugs, the highest non-compliance rate was observed in patients who were treated with interferon beta-1b (47\%), followed by interferon beta-1a (30\%) and glatiramer acetate $(26 \%)$.

There was a statistically significant association between treatment adherence and the following variables: older age (mean of 40.4 years in non-compliance patients vs 45.2 years in compliance patients, $P=0.013$ ); more treatments received; time to diagnosis 5-10 years; better cognitive and memory status; being married/in a union; having received clear information about the treatment; and higher satisfaction with the current administration route (Table 4).

The main cause for non-compliance was forgetfulness (27\%), which was found to be significantly associated with SC and oral routes (SC: $30 \%, P=0.005$; oral: $36 \%, P=0.005$ ) rather than IV ( $0 \%)$; Table 3 . Only $5 \%, 1 \%$, and $2 \%$ of patients stated non-compliance in the remaining MG test items, 2, 3 and 4 , respectively.

Among patients who sometimes forgot their medication in the last 6 months, $37 \%$ did so during the last month, with higher percentages in oral than injectable medication $(43 \%$ vs $32 \%)$. The reasons for forgetting were the following: absent-mindedness (42\%); leisure time (9\%); traveling (9\%); scheme confusion (7\%); lack of foresight (7\%); and other (discomfort with carrying it; job; welfare; malaise; and boredom) (18\%). Patients' actions after forgetting an intake were the following: waiting until the next intake (51\%); taking the medication once they realized it had been forgotten (21\%); taking two doses in the next administration (5\%); waiting until the next intake if more than 4 hours had passed (5\%); other (7\%); and not known/no answer (11\%). 
Table 4 Adherence to treatment in MS patients

\begin{tabular}{|c|c|c|c|}
\hline$N=157$ & $\begin{array}{l}\text { Compliance (\%) } \\
(n=I \mid 2)\end{array}$ & $\begin{array}{l}\text { Non-compliance }(\%) \\
(n=45)\end{array}$ & $P$-value \\
\hline \multicolumn{4}{|l|}{ Age (years) } \\
\hline$<40$ & 34 & 49 & 0.118 \\
\hline $40-49$ & 34 & 31 & 0.879 \\
\hline$\geq 50$ & 32 & 20 & 0.185 \\
\hline Mean & 45.2 & 40.4 & 0.013 \\
\hline \multicolumn{4}{|l|}{ Gender } \\
\hline Male & 27 & 31 & 0.727 \\
\hline Female & 73 & 69 & 0.727 \\
\hline \multicolumn{4}{|l|}{ MS type } \\
\hline RRMS & 72 & 80 & 0.426 \\
\hline SPMS & 21 & 13 & 0.410 \\
\hline PPMS & 7 & 7 & 1.000 \\
\hline \multicolumn{4}{|l|}{ Number of treatments } \\
\hline Mean & 2.0 & 1.6 & 0.046 \\
\hline \multicolumn{4}{|l|}{ Patients associations } \\
\hline Yes & 46 & 49 & 0.918 \\
\hline No & 54 & 51 & 0.918 \\
\hline \multicolumn{4}{|l|}{ Diagnosis (years) } \\
\hline$<5$ & 19 & 38 & 0.021 \\
\hline $5-10$ & 36 & 18 & 0.035 \\
\hline$>10$ & 45 & 44 & 1.000 \\
\hline Mean & 10.7 & 8.9 & 0.152 \\
\hline \multicolumn{4}{|c|}{ Exacerbation incidence focused on the last year } \\
\hline Exacerbations & 30 & 33 & 0.862 \\
\hline No exacerbations & 70 & 67 & 0.862 \\
\hline Exacerbations (mean) & 1.6 & 1.3 & 0.474 \\
\hline \multicolumn{4}{|l|}{ Exacerbation incidence } \\
\hline Months since last exacerbation (mean) & 32.9 & 27.0 & 0.329 \\
\hline \multicolumn{4}{|l|}{ Affectation/disability due to MS } \\
\hline With affectation/disability & 72 & 71 & 1.000 \\
\hline Without affectation/disability & 28 & 27 & 1.000 \\
\hline $\mathrm{Nk} / \mathrm{Na}$ & 0 & 2 & 1.000 \\
\hline \multicolumn{4}{|l|}{ Cognitive affectation due to MS } \\
\hline Cognitive affectation & 3 & 19 & 0.002 \\
\hline Memory loss & 1 & 16 & 0.002 \\
\hline \multicolumn{4}{|l|}{ Marital status } \\
\hline Married & 63 & 42 & 0.025 \\
\hline Not married & 37 & 58 & 0.025 \\
\hline \multicolumn{4}{|l|}{ Issues associated with medication } \\
\hline Medication importance (mean) & 9.1 & 9.2 & 0.713 \\
\hline Importance of following indications (mean) & 9.5 & 9.4 & 0.569 \\
\hline Clear information (mean) & 8.9 & 8.4 & 0.028 \\
\hline \multicolumn{4}{|l|}{ Current treatment } \\
\hline Current oral treatment & 33 & 49 & 0.940 \\
\hline Current injectable treatment & 67 & 51 & 0.940 \\
\hline Current medication, months (mean) & 43.7 & 56.7 & 0.100 \\
\hline \multicolumn{4}{|l|}{ Satisfaction with the current administration } \\
\hline Satisfaction with oral treatment (mean) & 9.1 & 8.0 & 0.016 \\
\hline Satisfaction with injectable treatment (mean) & 7.9 & 6.5 & 0.011 \\
\hline \multicolumn{4}{|c|}{$\begin{array}{l}\text { Patients' profile according to their attitude toward the } \\
\text { disease }\end{array}$} \\
\hline Pragmatic & 49 & 60 & 0.796 \\
\hline Proactive and realistic & 35 & 31 & 0.359 \\
\hline Unoptimistic & 16 & 9 & 0.246 \\
\hline
\end{tabular}

Note: Bold values indicate statistical significance.

Abbreviations: MS, multiple sclerosis; Nk/Na, not known/not available; PPMS, primary progressive multiple sclerosis; RRMS, relapsing-remitting multiple sclerosis; SPMS, secondary progressive multiple sclerosis. 
Fifty-one percent of patients did not express medication forgetfulness. The patients who did communicated this mainly to their doctor (33\%: always [86\%] and sometimes [14\%]), to a nurse professional (23\%: always [70\%], sometimes [30\%]), or to a pharmacist (2\%).

Regarding voluntary non-adherence, only $1 \%$ of MS patients reported voluntarily stopping the treatment in the last 30 days due to laziness or feeling unwell. Considering a prolonged evaluation period (the last 6 months), $5 \%$ of patients reported treatment interruption ( $71 \%$ by a physician's decision; $29 \%$ by their own decision [due to other drug administration, or because they felt unwell due to medication]). During this 6-month period, the mean number of interruptions was 1 , and the mean duration of treatment was 67.5 days.

\section{Previous treatment and reasons for change}

Fifty-two percent of patients previously received a different type of treatment: oral (10\%), injectable (86\%: 21\% IV and $79 \%$ SC), and unknown (4\%). The previous mean treatment duration ranged from 26.0 to 122.8 months: oral from 12.0 to 26.0 months, and injectable from 12.0 to 122.8 months.

The persons who initiated the change in medication were the following: the physician (94\%); the patient (13\%); or the nurse (1\%). The reasons were the following: lack of efficacy/presence of exacerbations (38\%); feeling unwell (37\%); uncomfortable to take (19\%); hepatic problems (6\%); virus infection (5\%); virus prevention (3\%); and other (8\%).

\section{Patient profiles according to their attitude toward the disease}

Three attitudinal patient types were reported as the following: pragmatic (52\%); proactive and realistic (34\%); and unoptimistic (14\%). There were no differences in adherence levels between these patient profiles.

\section{Discussion}

This study aims to determine the adherence to treatment of MS patients in Spain, according to the influence of several variables. The adherence rate observed was $71 \%$, slightly higher than that of another Spanish study using the same test $(68 \%)^{8}$ as well as those of additional studies in other countries conducted with MG tests (46\%) and Medication Possession Ratio (54\%). . $^{17,18}$

Regarding the administration route, our results show a higher adherence with injectable forms $(77 \%$ : $68 \%$ SC and $100 \%$ IV, vs oral [63\%]). In general, the injectable and SC results were considered as falling within acceptable limits, showing a higher percentage than that observed in another study with oral and self-injectable administrations in MS patients, although this study used another adherence method. ${ }^{18}$ It is important to highlight that IV administration is more adherent than SC and oral administrations. This difference could be explained by the different administration schedule for IV treatment, which is less frequent. With regard to this, a study showed that adherence increased in treatments with lower administration frequency. ${ }^{19}$ This difference in adherence could also be explained by the fact that the IV route is administered by health care professionals by medical appointment, whereas the SC and oral routes are administered by patients themselves. ${ }^{19,20}$ Some hospitals issue reminders for patients to come in for treatment, but we cannot state that this is a homogenous practice in Spain. Therefore, we have concluded that both reasons could be plausible explanations for the difference in adherence.

The main cause reported for non-compliance was forgetfulness. This unintentional behavior has been broadly observed as the main cause of non-adherence in MS patients. ${ }^{17,21,22}$ In our study, there was no difference in adherence between SC and oral administration, as another previous study showed..$^{18}$ However, both routes were significantly associated with forgetfulness, compared with IV administration. As noted previously, this could be due to a direct relationship between adherence and lower administration frequency, ${ }^{19,23}$ or a result of medical reminders for IV treatments.

Several variables were positively associated with adherence: older age; more treatments received; time to diagnosis 5-10 years; better cognitive status; fewer memory problems; being married/in a union; having received clear information about the disease; and higher treatment satisfaction. Despite these variables being associated with adherence, when we assessed attitudinal patient profiles, no differences in adherence were found. Therefore, it is difficult to establish a profile of patient compliance.

With regard to age, it has been noted that younger age is significantly associated with high adherence, but this was based on the number of injections administered in the previous month and interferon beta- $1 \mathrm{~b}$ only. ${ }^{8}$ However, other studies have also shown that patients aged $\geq 45$ years are more likely to be adherent, ${ }^{24}$ and there is a positive change in the probability of being adherent as age increases. ${ }^{24,25}$ This latest study is in concordance with the result that we observed, which may additionally justify the association of $<5$ years of diagnosis with non-compliance, despite several studies associating shorter durations of the disease with greater adherence to treatment. ${ }^{17,26}$ On the other hand, 
our study showed that higher age was positively associated with adherence, independent of the injectable route (IV or SC). It was not surprising that a better cognitive status over the years was associated with greater adherence. The impact of the cognitive status was corroborated by the poor adherence found in patients with cognitive impairment. ${ }^{24,27}$

Family and social environment are important factors in adherence, and living alone is a factor of non-compliance. ${ }^{28}$ Our results show a positive correlation between being married/ in a union and adherence; almost all patients feel extrinsically motivated by their family to adhere to treatment. ${ }^{17}$

Clear information about the disease promotes better adherence, and, therefore, misinformation and lack of understanding of the disease are associated with non-compliance. ${ }^{27}$ More information and higher awareness (which could have been acquired during previous treatments) would explain the result in our study of greater adherence being associated with more treatments received. This would also indicate that treatment adherence can be a representative marker of patients' behavior regarding their health. ${ }^{29}$ In this sense, our patients with concomitant diseases showed a high level of compliance, indicating that these patients tend to be compliant in general.

Treatment satisfaction was higher in oral administration than in injectable, and both were significantly higher in compliant patients. Several studies have shown that satisfaction is a determinant of adherence $\mathrm{e}^{30-32}$ and is associated with fewer relapses, a longer duration of medication, a lower disability score, and the absence of several side effects. ${ }^{10}$ Despite our patients showing high satisfaction with oral administration, adherence to this type of treatment was lower. Satisfaction with injectable administration was also significantly higher in adherent patients, supporting the levels of adherence observed. It is known that the main reasons for lack of satisfaction are treatment inconvenience (needing regular injections can affect acceptance of treatment), injection burden of IV, injectable DMTs, and injection site reactions. ${ }^{33,34}$ In this context, our patients who received medication with IV administration showed a statistically higher concern for these possible mild side effects; this was primarily true for young people and women, who also showed higher levels of compliance.

The compliance group was defined as, patients who were older, received more treatments, were diagnosed less than 10 years ago, possessed a better cognitive state, were married/in a union, received clear information about the disease, and showed high levels of satisfaction with the treatment. The compliance group was formed exclusively by individuals who presented a score of 0 in the MG test, and the non-compliance group was comprised those that scored 1 or higher.

With regard to the current treatment received and its impact, most patients were receiving an injectable treatment. The injectable route continues to be the preferred route and was the first route established with a well-defined and easily treatable adverse effect profile. ${ }^{33}$ Other worrying concerns related to treatment found in our study were the following: possible serious side effects, slowness of effect/benefit, the medication's impact on daily life, form of the treatment administration, and potential interference with pregnancy. These concerns have previously been shown in similar populations. ${ }^{10,33,34}$

Although satisfied with their current treatment, $52 \%$ of patients previously received a different type of treatment. Reasons to change were mainly related to the treatment itself and not to patient preference. These reasons were the following: inconvenience of the administration regimen; side effects; flu-like symptoms; and lack of efficacy, as shown by other studies. ${ }^{10,33,35}$ The change of treatment was initiated by a physician or nurse, although nowadays patient preferences play a major role in treatment decisions. ${ }^{5}$ In this sense, convenience of administration and the ease of safety monitoring in the long-term course of oral treatment are essential to patient satisfaction and adherence, showing that satisfaction is a determinant of adherence. ${ }^{30-32}$ However, according to our results, patients receiving oral treatment are less adherent. As in other studies, the drug administration frequency and medical reminders for IV treatments most likely play a greater role in adherence. ${ }^{19,23}$

Limitations of this study should be considered when interpreting its findings. Only one method to evaluate adherence was employed. Although this method is widely used, in order to confirm this result, it is necessary to use other methods. Due to the reduced sample size, these results should be treated with caution and considered as a first approach. In addition, the patients who agreed to participate and answer the questionnaire may represent a group of the population that is more actively engaged with their disease, leading to a higher level of adherence being observed in the present study.

\section{Conclusion}

Our study shows an acceptable adherence rate (71\%), associating several factors to an adherent patient profile (treatment, disease, and personal characteristics). Patients gave high importance to their disease and showed a reasonable level of satisfaction with their current treatment. Though 
satisfaction is related to adherence (and satisfaction was higher with oral treatments), oral administration showed a lower level of adherence. This may be due to the fact that the main cause of lack of adherence in MS patients is forgetfulness, and, therefore, other variables have greater importance, such as cognitive status and family support. A deep understanding of adherence rates is necessary when considering future strategies to improve clinical results and reduce non-pharmacological costs.

\section{Acknowledgments}

We gratefully acknowledge Amber for their contribution to data collection and statistical analysis (particularly Antonio Bermejo, Eva Figueras, and Olga Lluch). Writing and editorial assistance for the manuscript was provided by Sergio Alonso from Lidesec. This study was supported by Roche Farma S.A., Spain.

\section{Author contributions}

All authors contributed toward data analysis, drafting and revising the paper. gave approval of the final version to be published and agree to be accountable for all aspects of the work.

\section{Disclosure}

Raquel Fernández-Del Olmo has disclosed that she is an employee of Roche Farma, S.A. The authors report no other conflicts of interest in this work.

\section{References}

1. National Clinical Guideline Centre (UK). Multiple Sclerosis: Management of Multiple Sclerosis in Primary and Secondary Care. London: National Institute for Health and Care Excellence (UK); 2014 Oct. (NICE Clinical Guidelines, No. 186.) Available from: https://www.ncbi.nlm. nih.gov/books/NBK248064/. Accessed 20 February, 2018.

2. Kobelt G, Thompson A, Berg J, et al. New insights into the burden and costs of multiple sclerosis in Europe. Mult Scler. 2017;23(8):1123-1136.

3. Hauser SL, Chan JR, Oksenberg JR. Multiple sclerosis: prospects and promise. Ann Neurol. 2013;74(3):317-327.

4. Nylander A, Hafler DA. Multiple sclerosis. J Clin Invest. 2012;122(4): $1180-1188$.

5. Bayas A, Mäurer M. Teriflunomide for the treatment of relapsingremitting multiple sclerosis: patient preference and adherence. Patient Prefer Adherence. 2015;9:265-274.

6. MSFI. Atlas of MS 2013: mapping multiple sclerosis around the world (pdf). Multiple Sclerosis International Federation; 2013. Available from: http://www.msif.org/wp-content/uploads/2014/09/Atlas-of-MS.pdf. Accessed 20 February 2018.

7. Gold LS, Suh K, Schepman PB, Damal K, Hansen RN. Healthcare costs and resource utilization in patients with multiple sclerosis relapses treated with H.P. Acthar Gel®. Adv Ther. 2016;33(8):1279-1292.

8. Fernández $\mathrm{O}$, Agüera $\mathrm{E}$, Agüera $\mathrm{J}$, et al. Adherence to interferon $\beta-1 \mathrm{~b}$ treatment in patients with multiple sclerosis in Spain. PLoS One. 2012;7(5):e35600.
9. Sicras-Mainar A, Ruíz-Beato E, Navarro-Artieda R, Maurino J. Impact on healthcare resource utilization of multiple sclerosis in Spain. $B M C$ Health Serv Res. 2017;17(1):854.

10. Haase R, Kullmann JS, Ziemssen T. Therapy satisfaction and adherence in patients with relapsing-remitting multiple sclerosis: the THEPA-MS survey. Ther Adv Neurol Disord. 2016;9(4):250-263.

11. Osterberg L, Blaschke T. Adherence to medication. $N$ Engl J Med. 2005;353(5):487-497.

12. Steinberg SC, Faris RJ, Chang CF, Chan A, Tankersley MA. Impact of adherence to interferons in the treatment of multiple sclerosis: a nonexperimental, retrospective, cohort study. Clin Drug Investig. 2010;30(2): 89-100.

13. Evans C, Marrie RA, Zhu F, et al. Adherence and persistence to drug therapies for multiple sclerosis: a population-based study. Mult Scler Relat Disord. 2016;8:78-85.

14. Mckay KA, Tremlett H, Patten SB, et al. Determinants of non-adherence to disease-modifying therapies in multiple sclerosis: a cross-Canada prospective study. Mult Scler. 2017;23(4):588-596.

15. Morisky DE, Green LW, Levine DM. Concurrent and predictive validity of a self-reported measure of medication adherence. Med Care. 1986; 24(1):67-74.

16. García Pérez AM, Leiva Fernández F, Martos Crespo F, García Ruíz AJ, Prados Torres D, Sánchez de la Cuesta y Alarcón F. ¿Cómo diagnosticar el cumplimiento terapéutico en atención primaria? [How to diagnose therapeutic compliance in primary care?]. Medicina de Familia. 2000;1:13-19.

17. Câmara NAAC, Gondim APS. Factors associated with adherence to immunomodulator treatment in people with multiple sclerosis. Braz J Pharm Sci. 2017;53(1):e16132.

18. Munsell M, Frean M, Menzin J, Phillips AL. An evaluation of adherence in patients with multiple sclerosis newly initiating treatment with a self-injectable or an oral disease-modifying drug. Patient Prefer Adherence. 2017;11:55-62.

19. Huynh TK, Ostergaard A, Egsmose C, Madsen OR. Preferences of patients and health professionals for route and frequency of administration of biologic agents in the treatment of rheumatoid arthritis. Patient Prefer Adherence. 2014;8:93-99.

20. Society NMS. Los Medicamentos Modificadores de la Esclerosis Múltiple. In: Vol 1-36; 2016. Available from: https://www.nationalmssociety.org/NationalMSSociety/media/MSNationalFiles/Brochures/ Brochure-Los-Medicamentos-Modificadores-de-la-Esclerosis-Multiple. pdf. National Multiple Sclerosis Society. Accessed 11 January, 2019.

21. Devonshire V, Lapierre Y, MacDonell R, et al. The Global Adherence Project (GAP): a multicenter observational study on adherence to disease-modifying therapies in patients with relapsing-remitting multiple sclerosis. Eur J Neurol. 2011;18(1):69-77.

22. Pozo M, Alonso M, Martos M, Salvador F, Martínez C. Adherence to treatment by public administration workers: factors related to health and well-being. Medicina y Seguridad del Trabajo. 2009;55(215): 63-71.

23. Halpern R, Agarwal S, Dembek C, Borton L, Lopez-Bresnahan M. Comparison of adherence and persistence among multiple sclerosis patients treated with disease-modifying therapies: a retrospective administrative claims analysis. Patient Prefer Adherence. 2011;5:73-84.

24. Higuera L, Carlin CS, Anderson S. Adherence to disease-modifying therapies for multiple sclerosis. J Manag Care Spec Pharm. 2016;22(12): 1394-1401.

25. OdlAa T. Adherencia al tratamiento en la Comunidad de Madrid. Available from: link:https://www.sefac.org/sites/default/files/sefac2010/ private/documentos_sefac/documentos/farmaindustria-plan-deadherencia.pdf. Accessed 17 November, 2017.

26. Remington G, Rodriguez Y, Logan D, Williamson C, Treadaway K. Facilitating medication adherence in patients with multiple sclerosis. Int J MS Care. 2013;15(1):36-45.

27. Holland N, Wiesel P, Cavallo P, et al. Adherence to disease-modifying therapy in multiple sclerosis: part I. Rehabil Nurs. 2001;26(5):172-176. 
28. Conthe P, Márquez Contreras E, Aliaga Pérez A, et al. Adherencia terapéutica en la enfermedad crónica: estado de la situación y perspectiva de futuro [Therapeutic adherence in chronic disease: status of the situation and perspective for the future]. Revista Clinica Española. 2014;214(6):336-344

29. Simpson SH, Eurich DT, Majumdar SR, et al. A meta-analysis of the association between adherence to drug therapy and mortality. BMJ. 2006;333(7557):15.

30. Chrystyn H, Small M, Milligan G, Higgins V, Gil EG, Estruch J. Impact of patients' satisfaction with their inhalers on treatment compliance and health status in COPD. Respir Med. 2014;108(2):358-365.

31. Wong WS, Chow YF, Chen PP, Wong S, Fielding R. A longitudinal analysis on pain treatment satisfaction among Chinese patients with chronic pain: predictors and association with medical adherence, disability, and quality of life. Qual Life Res. 2015;24(9):2087-2097.
32. Zimmer A, Bläuer C, Coslovsky M, Kappos L, Derfuss T. Optimizing treatment initiation: Effects of a patient education program about fingolimod treatment on knowledge, self-efficacy and patient satisfaction. Mult Scler Relat Disord. 2015;4(5):444-450.

33. Fernández O, Duran E, Ayuso T, et al. Treatment satisfaction with injectable disease-modifying therapies in patients with relapsingremitting multiple sclerosis (the STICK study). PLoS One. 2017;12(10): e0185766.

34. Johnson KM, Zhou H, Lin F, Ko JJ, Herrera V. Real-world adherence and persistence to oral disease-modifying therapies in multiple sclerosis patients over 1 year. J Manag Care Spec Pharm. 2017;23(8): 844-852.

35. Giovannoni G, Southam E, Waubant E. Systematic review of diseasemodifying therapies to assess unmet needs in multiple sclerosis: tolerability and adherence. Mult Scler. 2012;18(7):932-946.

\section{Publish your work in this journal}

Patient Preference and Adherence is an international, peer-reviewed, open access journal that focuses on the growing importance of patient preference and adherence throughout the therapeutic continuum. Patient satisfaction, acceptability, quality of life, compliance, persistence and their role in developing new therapeutic modalities and compounds to optimize clinical outcomes for existing disease states are major areas of interest for the journal. This journal has been accepted for indexing on PubMed Central. The manuscript management system is completely online and includes a very quick and fair peer-review system, which is all easy to use. Visit http://www dovepress.com/testimonials.php to read real quotes from published authors. 